\title{
Significance of Ovarian Function Suppression in Endocrine Therapy for Breast Cancer in Pre-Menopausal Women
}

\author{
Bedeutung der Ovarialsuppression in der endokrinen Therapie \\ des Mammakarzinoms der prämenopausalen Frau
}

Authors

Affiliations
A. Scharl ${ }^{1}$, A. Salterberg ${ }^{2}$

${ }^{1}$ Gynaecological Hospital, Klinikum St. Marien Amberg, Amberg

${ }^{2}$ Department of Gynaecology and Obstretrics, Sana Kliniken of the County of Cham, Cham
Key words
- pre-menopause
- breast cancer
- compliance
- ovarian function suppression
- tamoxifen
- aromatase inhibitors
Schlüsselwörter
- Prämenopause
- Mammakarzinom
- Compliance
- Ovarialsuppression
- Tamoxifen
- Aromatasehemmer

Deutsche Version unter: http://dx.doi.org/ 10.1055/s-0042-106389

received 4.1.2016 revised 11.4.2016 accepted 11.4.2016

\section{Bibliography}

DoI http://dx.doi.org/ 10.1055/s-0042-106389

Geburtsh Frauenheilk 2016; 76: 516-524 @ Georg Thieme Verlag KG Stuttgart · New York . ISSN 0016-5751

\section{Correspondence}

Professor Anton Scharl

Klinikum St. Marien Amberg Mariahilfbergweg 7

92224 Amberg

scharl.anton@

klinikum-amberg.de

\section{Abstract \\ $\nabla$}

Ovarian function suppression (OFS) for treating breast cancer in pre-menopausal women was introduced for the first time in the late 19th century as bilateral oophorectomy. It was not until the 1960s that the oestrogen receptor was identified and a test for detecting endocrine sensitivity of the breast cancer was developed. A weakness of early trials on OFS for breast cancer treatment is therefore their failure to take receptor sensitivity into account when selecting participants. A metaanalysis performed in the early 1990s first proved that adjuvant OFS significantly improved the cure rate of oestrogen receptor-positive breast cancer in pre-menopausal women regardless of whether it was carried out through oophorectomy, radiation-induced ablation or drug therapy. In the 1970 s, tamoxifen was synthesized. It became one of the most important cancer drugs and today constitutes the gold standard for endocrine adjuvant therapy. Taking tamoxifen for a five-year period lowers mortality by $30 \%$ over 15 years. Ten years of tamoxifen therapy reduces mortality even further, with increased side effects, however. Research over the past ten years has proven that for post-menopausal women, aromatase inhibitors have benefits over tamoxifen. Current trial results have rekindled the debate about the combination of OFS with tamoxifen or with aromatase inhibitors for adjuvant breast cancer treatment of pre-menopausal women. These trials have reported an improvement in disease-free survival in patients with a high risk of recurrence when they are treated with a combination of OFS plus tamoxifen or aromatase inhibitors, especially in women younger than 35 . However, combination therapy causes significantly more side effects, which could negatively impact compliance. Endocrine treatments administered over a period of many years show waning compliance, which tends to be only around $50 \%$ after five years. Inad-

\section{Zusammenfassung}

$\nabla$

Die Ovarialsuppression als Therapie des Mammakarzinoms der prämenopausalen Frau wurde erstmals Ende des 19. Jahrhunderts als bilaterale Ovarektomie durchgeführt. Erst in den 1960erJahren wurde der Östrogenrezeptor identifiziert und ein Test zum Nachweis der endokrinen Sensitivität des Mammakarzinoms entwickelt. Die frühen Studien zur OFS beim Mammakarzinom leiden daher darunter, dass keine Selektion nach Rezeptorpositivität des Tumors erfolgte. Erst eine Metaanalyse Anfang der 1990er-Jahre konnte nachweisen, dass die adjuvante Ovarialsuppression zu einer deutlichen Verbesserung der Heilungsrate des rezeptorpositiven Mammakarzinoms der prämenopausalen Frau führt, unabhängig davon, ob sie durch Ovarektomie, Radiokastration oder medikamentös erfolgt. In den 1970er-Jahren wurde Tamoxifen synthetisiert. Durch glückliche Zufälle wurde es zu einem der wichtigsten onkologischen Medikamente und ist heute der Goldstandard der endokrinen adjuvanten Therapie. Eine 5-jährige Einnahme senkt die Mortalität über 15 Jahre um 30\%; die 10-jährige Tamoxifentherapie ermöglicht eine zusätzliche Mortalitätssenkung allerdings bei Zunahme der Nebenwirkungen. Für postmenopausale Frauen wurde im letzten Jahrzehnt nachgewiesen, dass Aromatasehemmer gegenüber Tamoxifen Vorteile aufweisen. Aktuelle Studienergebnisse entfachten die Diskussion über die Kombination von Ovarialsuppression mit Tamoxifen oder mit Aromatasehemmern zur adjuvanten Therapie prämenopausaler Patientinnen neu. Sie hatten eine Verbesserung des krankheitsfreien Überlebens bei Patientinnen mit hohem Rezidivrisiko durch Kombination von Ovarialsuppression mit Tamoxifen oder Aromatasehemmern v.a. bei Frauen unter 35 Jahren gezeigt. Allerdings hat die Kombinationstherapie deutlich mehr Nebenwirkungen, was die Compliance negativ beeinflussen könnte. 
equate compliance compromises efficacy and increases the risk of mortality. For this reason, when indicating and supporting endocrine adjuvant therapy, physicians must ensure that compliance will be good. To prevent recurrence in the long run, it is much more effective to prescribe a somewhat less effective therapy that will actually be carried out than to prescribe one that is theoretically more effective, but is not adhered to consistently.

"Treatment can only be successful if it is actually carried out."

\section{Introduction}

$\nabla$

Endocrine therapy for breast cancer treatment is the oldest targeted therapy. Around 70 to $80 \%$ of breast cancer tumours express oestrogen receptors (ORs) and/or progesterone receptors (PRs). These hormone receptor-sensitive tumours can be treated by modifying the endocrine milieu. Generally, this can be achieved through ablative therapy, in which the body's own oestrogen production is suppressed. In pre-menopausal women, this is achieved with ovarian function suppression (OFS) by means of bilateral oophorectomy, radiation-induced ablation or chemical suppression with GnRH analogues. For ablation in post-menopausal women without functioning ovaries, aromatase inhibitors (AIs) are used to suppress the enzyme aromatase, which reduces the formation of oestrogen in peripheral tissue. A second option for endocrine therapy involves selective blockade of the hormone receptors with selective oestrogen receptor modulators (SERMs), among which tamoxifen (TAM) is most commonly used. For premenopausal women, tamoxifen is the gold standard for adjuvant endocrine therapy. Depending on the tumour biology and risk level, chemotherapy ( \pm anti-HER2 therapy) is sometimes administered prior to tamoxifen treatment [1].

Historically, oophorectomy was the first somewhat regularly used endocrine adjuvant therapy for pre-menopausal breast cancer patients. Love and Philips [2] compared oophorectomy to taking aspirin for health: "it keeps reappearing as an effective therapy with new twists". In fact, the significance of OFS as an adjuvant to tamoxifen has been debated for decades. Opinions about the use of OFS have fluctuated regularly depending on the different interpretations of the same, relatively old database. The AGO Breast Committee Guidelines issued over the past 15 years are a good reflection of this. Furthermore, in the past decade it was shown that for post-menopausal breast cancer patients, AIs have some advantages over TAM. It would therefore appear to be worthwhile to use OFS to render pre-menopausal patients postmenopausal in order for them to benefit from the advantages of AI therapy.

The first published results of new trials (ABCSG-12, TEXT, SOFT) have fuelled this debate and have led to considerable uncertainty about the "right" therapy [3-6].

This article therefore aims to describe the clinical role of OFS today.
Die jahrelangen endokrinen Therapien leiden unter einer abnehmenden Compliance, die nach 5 Jahren in der Regel nur noch bei $50 \%$ liegt. Eine unzureichende Compliance vermindert den Effekt und erhöht das Mortalitätsrisiko. Daher muss bei der Indikationsstellung und Begleitung der endokrinen adjuvanten Therapie auf eine gute Compliance geachtet werden. Eine tatsächlich durchgeführte Therapie, mit evtl. etwas geringerer Wirkung kann onkologisch sinnvoller sein als eine prinzipiell wirksamere Behandlung, die aber nicht konsequent durchgeführt wird.

\section{Oophorectomy for Breast Cancer Treatment}

In 1882, long before German Nobel laureate Adolf Butenandt discovered and isolated the female sex hormones in 1929, English physician Thomas William Nunn proposed an association between the ovaries and breast cancer. Nunn had observed a regression of breast cancer in a patient 6 months after she entered menopause. German surgeon Albert Schinzinger also observed that the prognosis of breast cancer in older women appeared to be better than for younger women and speculated that performing oophorectomy would cause the women to age prematurely, causing the mammary gland to atrophy, along with any breast tumour. At the 18th congress of the German Society for Surgery in 1889 , Schinzinger therefore proposed surgical oophorectomy as a treatment for advanced breast cancer and to prevent recurrence. Schinzinger, however, never performed the surgery himself and apparently was unable to convince his fellow surgeons to use the procedure [2].

Scottish surgeon George Thomas Beatson also considered oophorectomy as a treatment for breast cancer, since castration was used to prevent lactation in cattle. In 1895, Beatson performed the first bilateral oophorectomy in a breast cancer patient with extensive recurrence and subsequently reported the patient's complete remission. This constituted the first application of ablative endocrine therapy for breast cancer. English surgeon Stanley Boyd then performed the first bilateral oophorectomy as adjuvant breast cancer treatment in 1897. He also developed a hypothesis about the mechanisms that appeared to be at work, which foreshadowed our current knowledge: "My working hypothesis is that internal secretion of the ovaries in some cases favours the growth of the cancer". In 1900, Boyd published a summary of his cases in which he reported that one third of the patients had clearly benefited from the procedure [2].

However, due to the very high rate of morbidity and mortality associated with the procedure at the time, bilateral oophorectomy therapy did not become established. It was not until the $1950 \mathrm{~s}$ that the U.S. Nobel laureate Charles Huggins and his research assistant Thomas Dao again brought oophorectomy, now combined with adrenalectomy, to the focus of cancer treatment [2].

At the time, however, it was not yet possible to predict which patients would benefit from ablative hormone therapy. Elwood Jensen's ground-breaking studies finally made this possible. Jensen synthesized tritium-labelled oestradiol and in 1962, demonstrated that in rats, the steroid was bound only to target organs for oestrogen (e.g. the uterus) and not to tissue not sensitive to oestrogen (e.g. lung, skeletal muscle). Based on these findings, Jensen developed the concept of an oestrogen receptor that would mediate the effect of oestrogen in the target tissue. In 1971, he described a predictive test that he used to determine the presence of this receptor protein in breast cancer cytosols and reliably predict the effect of the ablative therapy [7]. In the 1990s, the test 
from the cytosol was replaced by immunohistological determination of the receptor protein and this test is still performed today [8].

In the 1960s and 1970s, several small-scale randomized trials on adjuvant OFS in pre-menopausal breast cancer patients were conducted. The general consensus was that these trials did not demonstrate any benefit of the therapy [2]. This opinion was not shifted until 1992, when the Early Breast Cancer Trialists' Collaborative Group (EBCTCG)'s meta-analysis of updated data from these trials was performed, which clearly demonstrated the direct long-term benefits of adjuvant OFS. This report and the updated analysis performed in 2005 proved that disease-free survival (DFS) and overall survival (OS) in receptor-positive tumours were clearly improved. However, even after Jensen's development of receptor determination, it still took several decades for testing the receptor status to become established as the clinical standard. This means that many studies on endocrine therapy for breast cancer treatment, especially the EBCTCG meta-analyses, also include data from patients in whom the receptor status was not determined and thus also include receptor-negative tumours $[9,10]$.

In the 1990s and early 2000s, several randomized trials were published that showed that chemical OFS (with GnRH agonists) or surgical OFS in women with receptor-positive, node-positive or node-negative tumours were at least as effective as chemotherapy with cyclophosphamide, methotrexate and fluorouracil (CMF) or even with anthracyclines [11-15]. However, no comparison has been undertaken with the third-generation chemotherapy containing taxanes commonly administered today, which is why OFS does not constitute an alternative to chemotherapy.

Moreover, in the meantime TAM has become established as an effective adjuvant endocrine therapy, with or without chemotherapy.

\section{Ovarian Failure Due to Chemotherapy}

In addition to its direct cytotoxic effect, adjuvant chemotherapy has an indirect endocrine effect in pre-menopausal women with receptor-positive tumours because it induces ovarian failure. Chemotherapy-induced amenorrhoea (CIA) favourably impacts survival, even if it is only temporary. The incidence of CIA is dependent on the patient's age and on the chemotherapy regimen. Incidence is highest among women older than 40 using alkylating agents (e.g. cyclophosphamide) [16-18].

\section{Tamoxifen}

$\nabla$

In the 1950s and 1960s, English endocrinologist Arthur L. Walphole and his team at ICI Pharmaceuticals worked on the development of anti-oestrogens with the aim of developing a morningafter contraceptive pill. In 1967, they synthesized the substance ICI-46,474 (later named tamoxifen). Up to the early 1970s, the working group's focus was only on reproductive endocrinology. While TAM was unsuitable as a contraceptive, however, it was approved for fertility treatment [7]

There were also indications of its efficacy for breast cancer treatment. However, for various reasons, including the prevailing opinion of the time that adjuvant endocrine therapy would not provide additional benefits for the existing range of breast cancer treatments, in 1972 ICI decided not to further pursue the oncological potential of ICI-46,474 [7].

Thanks to a number of coincidences, however, this potential was re-explored. A small-scale trial with ICI-46,474 for breast cancer treatment in post-menopausal women demonstrated efficacy and a favourable side-effect profile. Furthermore, the oncological effect was confirmed in many animal experiments. This served as the basis for further development, primarily advanced by the British-American physician V. Craig Jordan. As a result, TAM developed from a failed contraceptive to a pioneer substance for targeted cancer therapy and chemoprevention of breast cancer and was added to the World Health Organization (WHO)'s List of Essential Medicines [7].

Numerous studies tested the effect of TAM in metastatic and early breast cancer and demonstrated its efficacy with a good toxicity profile. The pharmacology of the SERMs was decoded in the 1980s. In the 1990s, five-year treatment with TAM became the therapy of choice for post-menopausal breast cancer patients [7].

However, it wasn't until 1998 that EBCTCG's meta-analysis definitely proved that several years of adjuvant TAM therapy of patients with receptor-positive breast cancer reduced mortality, regardless of age or menopausal status, while only 1 year of therapy is not effective, just as treatment of receptor-negative cancer [7]. A new EBCTCG meta-analysis of randomized trials performed in 2011 showed that 5 years of treatment with TAM reduced the recurrence rate over 10 years (by $47 \%$ in years 1 to 4 and by $32 \%$ in years 5 to 9 ). No further benefits were observed after 10 years of treatment. The use of TAM reduced breast cancer mortality over the entire 15-year observation period by around one third (around 29\% in years 1 to 4 , around 34\% in years 5 to 9 and around $32 \%$ in years 10 to 14 ). The benefits were independent of age, node status, tumour size or additional chemotherapy and were the same for both post-menopausal and pre-menopausal patients. However, the therapeutic effect can only be proven for receptor-positive tumours ( $\bullet$ Table 1 ). Major side effects were endometrial cancer and thromboembolic disease in women older than 55. The contralateral breast cancer incidence was reduced by $50 \%$ [19]. The effects of the adjuvant therapy with tamoxifen and chemotherapy are complementary. According to an EBCTCG meta-analysis treatment of women younger than 50 with tamoxifen after anthracycline-based chemotherapy reduces the 15year mortality rate by $57 \%$ [10].

The findings of the ATLAS trial demonstrate that no benefits are derived from TAM therapy extended to 10 years (compared to 5 years of TAM) in the first 10 years post-diagnosis. However, in the period after the first 10 years post-diagnosis, the recurrence rate is $25 \%$ lower and mortality is $29 \%$ lower. The 10 -year therapy reduces mortality in the first 10 years by a third and in the second ten years by $50 \%$ ( Table 2 ). The effects are independent of age and menopausal status. For 10 years of therapy, the incidence of endometrial cancer and pulmonary embolism is significantly increased, while contralateral breast cancer and ischemic heart disease are significantly reduced. With 10 years of TAM therapy compared to 5 years TAM therapy, absolute breast cancer mortality drops by $3 \%$, while non-breast cancer mortality increases by $0.2 \%$ [20]. In this trial, however, only $9 \%$ of the patients were pre-menopausal. The low number of cases most likely accounts for the fact that no statistical relevance was reached for pre-menopausal women. 
Table 1 Effect of 5 years of tamoxifen (TAM) therapy in patients with hormone-sensitive breast cancer. Breast cancer mortality and overall mortality in 2614 premenopausal women (younger than 45) and in 4373 post-menopausal women (between 55 and 69). Absolute mortality in per cent after 5,10 and 15 years of observation; absolute benefit and relative risk (RR) with $95 \%$ confidence intervals (Cls) after 15 years of observation. In the overall group, the effect of TAM therapy was independent of the application of chemotherapy $(\mathrm{N}+$ : percentage of women with node-positive tumours; chemotherapy: percentage of women who had undergone chemotherapy) (results of the EBCTCG meta-analysis of the randomized trials, modified after [19]).

\begin{tabular}{|c|c|c|c|c|c|c|c|c|c|c|c|}
\hline \multirow{3}{*}{$\begin{array}{l}\text { Age at } \\
\text { diag- } \\
\text { nosis }\end{array}$} & \multirow[t]{3}{*}{$\mathrm{N}+$} & \multirow{3}{*}{$\begin{array}{l}\text { Chemo- } \\
\text { therapy }\end{array}$} & \multirow{3}{*}{$\begin{array}{l}\text { Obser- } \\
\text { vation } \\
\text { period }\end{array}$} & \multicolumn{4}{|c|}{ Breast cancer mortality } & \multicolumn{4}{|c|}{ Overall mortality } \\
\hline & & & & \multicolumn{2}{|c|}{ Mortality in \% } & \multicolumn{2}{|c|}{ Benefits after 15 years } & \multicolumn{2}{|c|}{ Mortality in \% } & \multicolumn{2}{|c|}{ Benefits after 15 years } \\
\hline & & & & $\begin{array}{l}\text { Control } \\
\text { group }\end{array}$ & $\begin{array}{l}5 \text { years } \\
\text { TAM }\end{array}$ & $\begin{array}{l}\text { Abso- } \\
\text { lute }\end{array}$ & $\mathbf{R R}(\mathrm{Cl})$ & $\begin{array}{l}\text { Control } \\
\text { group }\end{array}$ & $\begin{array}{l}5 \text { years } \\
\text { TAM }\end{array}$ & $\begin{array}{l}\text { Abso- } \\
\text { lute }\end{array}$ & $\mathrm{RR}(\mathrm{Cl})$ \\
\hline \multirow[t]{3}{*}{$\begin{array}{l}<45 \\
\text { years }\end{array}$} & $44 \%$ & $79 \%$ & 5 years & 13.4 & 10.3 & 10.6 & $\begin{array}{l}0.71 \\
(0.62-0.83)\end{array}$ & 13.9 & 11.0 & 11.2 & $\begin{array}{l}0.71 \\
(0.62-0.83)\end{array}$ \\
\hline & & & 10 years & 28.0 & 21.0 & & & 29.0 & 22.0 & & \\
\hline & & & 15 years & 35.9 & 25.3 & & & 38.1 & 26.8 & & \\
\hline \multirow[t]{3}{*}{$\begin{array}{l}55-69 \\
\text { years }\end{array}$} & $27 \%$ & $24 \%$ & 5 years & 12.6 & 8.1 & 11.7 & $\begin{array}{l}0.63 \\
(0.56-0.71)\end{array}$ & 15.4 & 11.1 & 9.5 & $\begin{array}{l}0.78 \\
(0.71-0.85)\end{array}$ \\
\hline & & & 10 years & 26.4 & 16.4 & & & 33.0 & 23.7 & & \\
\hline & & & 15 years & 34.9 & 23.2 & & & 46.4 & 36.9 & & \\
\hline
\end{tabular}

Table 2 Results of the ATLAS trial. The results are presented for 6846 women with receptor-positive tumours who either discontinued TAM therapy after 5 years $(n=3418)$ or continued TAM therapy for a total of 10 years $(n=3428)$. The age distribution and distribution of menopausal status are presented. The recurrence rates and breast cancer mortality for different time periods after initiation of treatment are presented as relative risks ( $95 \%$ confidence interval). In so doing, the results of the EBCTCG meta-analysis (5 years of TAM vs. control group) (presented after [19]), the results of the ATLAS trial (5 vs. 10 years of TAM) and the hypothetical situation of 10 years of TAM vs. control group as an extrapolation from these two analyses are compared.

\begin{tabular}{|c|c|c|c|c|c|c|}
\hline \multicolumn{4}{|c|}{ Age (percentage in the groups with $10 / 5$ years of TAM) } & \multicolumn{3}{|c|}{ Menopausal status (percentage in the groups with $10 / 5$ years of TAM) } \\
\hline$<45$ years & $45-54$ years & $55-69$ years & $\geq 70$ years & Pre-menopausal & Peri-menopausal or not known & Post-menopausal \\
\hline $19 / 18$ & $32 / 32$ & $40 / 40$ & $9 / 10$ & $10 / 9$ & $2 / 2$ & $89 / 89$ \\
\hline \multicolumn{7}{|c|}{ Risk of recurrence } \\
\hline Years after & ent initiation & \multicolumn{2}{|c|}{5 years TAM vs. control group } & 5 vs. 10 years TAM & \multicolumn{2}{|l|}{10 years TAM vs. control group } \\
\hline $0-4$ years & & \multicolumn{2}{|c|}{$0.53(0.48-0.57)$} & 1 & \multicolumn{2}{|l|}{$0.53(0.48-0.57)$} \\
\hline $5-9$ years & & \multicolumn{2}{|c|}{$0.68(0.60-0.78)$} & $0.90(0.79-1.02)$ & \multicolumn{2}{|l|}{$0.61(0.51-0.73)$} \\
\hline$\geq 10$ years & & \multicolumn{2}{|c|}{$0.94(0.79-1.12)$} & $0.75(0.62-0.90)$ & \multicolumn{2}{|l|}{$0.70(0.54-0.91)$} \\
\hline \multicolumn{7}{|c|}{ Breast cancer mortality } \\
\hline Years after & ent initiation & \multicolumn{2}{|c|}{5 years TAM vs. control group } & 5 vs. 10 years TAM & \multicolumn{2}{|l|}{10 years TAM vs. control group } \\
\hline $0-4$ years & & \multicolumn{2}{|c|}{$0.71(0.62-0.80)$} & 1 & \multicolumn{2}{|l|}{$0.71(0.62-0.80)$} \\
\hline $5-9$ years & & \multicolumn{2}{|c|}{$0.66(0.58-0.75)$} & $0.97(0.79-1.18)$ & \multicolumn{2}{|l|}{$0.64(0.50-0.82)$} \\
\hline$\geq 10$ years & & \multicolumn{2}{|c|}{$0.73(0.62-0.86)$} & $0.71(0.58-0.88)$ & \multicolumn{2}{|l|}{$0.52(0.40-0.68)$} \\
\hline
\end{tabular}

The aTTom trial also compared 5 years of TAM therapy with 10 years of TAM therapy and presented similar results [21]. To date, this trial has been published only in abstract form. Combining the results of the aTTom and the ATLAS trials increases the statistical significance of the benefits of extended treatment with TAM with respect to the rate of recurrence, breast cancer mortality and overall mortality.

Study results also demonstrate that it is worthwhile to resume interrupted tamoxifen therapy and to initiate tamoxifen therapy even several years after breast cancer diagnosis. Even if tamoxifen therapy is initiated up to 5 years after diagnosis, DFS and OS benefits are derived after 10 years. In tamoxifen therapy initiated in patients more than 5 years after diagnosis, DFS is still significantly better than in patients who have not undergone TAM therapy [22].

\section{OFS versus Tamoxifen}

There are not enough data to make a reliable statement about the efficacy of TAM compared to OFS in pre-menopausal women. The only trial addressing this issue included only 320 patients in whom the receptor status was not always known. This trial did not observe any differences [23].

\section{Aromatase Inhibitors}

While in pre-menopausal women oestrogens are primarily produced in the ovaries, in post-menopausal women, oestrogens are produced in peripheral tissue through the conversion of other steroids by means of the enzyme aromatase. Aromatase inhibitors (AIs) suppress this enzyme conversion. For this reason, AIs are not effective in pre-menopausal women. In fact, the converse is true: the reduction in the peripheral oestrogen levels activates the hypothalamic-pituitary axis. This increases gonadotropin se- 
Table 3 Luteinizing hormone-releasing hormone agonists in adjuvant therapy of pre-menopausal patients with hormone receptor-positive breast cancer. Metaanalysis of individual patient data from randomized trials (modified after [29]) (RRR: relative risk reduction, Cl: $95 \%$ confidence interval, n: number of patients, Chemo: Chemotherapy, LHRH: ovarian function suppression with LHRH, TAM: tamoxifen).

\begin{tabular}{|c|c|c|c|c|}
\hline Age & $\mathbf{n}$ & RRR & $\mathrm{Cl}$ & p \\
\hline \multicolumn{5}{|c|}{ Chemo \pm LHRH } \\
\hline$<40$ years & 714 & -24.7 & -39.5 to 6.2 & 0.01 \\
\hline$>40$ years & 1662 & -5.1 & -20.1 to 12.7 & 0.55 \\
\hline \multicolumn{5}{|c|}{ Chemo + TAM \pm LHRH } \\
\hline$\leq 40$ years & 81 & -31.2 & -67.5 to 46.0 & 0.33 \\
\hline$>40$ years & 284 & 5.3 & -33.3 to 66.3 & 0.82 \\
\hline \multicolumn{5}{|c|}{ (Chemo \pm TAM) \pm LHRH (combination of previous comparisons: Chemo \pm LHRH and Chemo + TAM \pm LHRH) } \\
\hline$\leq 40$ years & 795 & -25.2 & -39.4 to -7.7 & 0.01 \\
\hline$>40$ years & 284 & -3.9 & - 18.1 to 12.9 & 0.63 \\
\hline
\end{tabular}

cretion, which stimulates the ovaries, resulting in increased oestrogen levels. This effect is helpful in reproductive medicine [24]. For this reason, AIs are not suitable for endocrine therapy for breast cancer treatment in pre-menopausal women.

Clinical trials on the application of AIs in adjuvant breast cancer therapy were analysed in a current EBCTCG meta-analysis of individual patient data. These trials included 31920 post-menopausal women with receptor-positive breast cancer. The randomized trials compared 5 years of AIs vs. 5 years of TAM, 5 years of AIs vs. 2 to 3 years of TAM, followed by AIs up to year 5 , and compared 2 to 3 years of TAM followed by AIs up to year 5 , all compared to 5 years of TAM. The analysis showed that compared to TAM, AIs reduced the recurrence rate by around 30\% as long as the different therapy continued, but not thereafter. Five years of Als reduce 10 -year breast cancer mortality by around $15 \%$ compared with 5 years of TAM and reduce 10 -year breast cancer mortality by around $40 \%$ compared to no endocrine therapy [25].

No differences in the efficacy of the available AIs in adjuvant therapy were observed, although there were slight differences in the side effect profile [26,27].

However, these data apply only to post-menopausal patients. AIs are contraindicated in pre-menopausal women; for these patients, AI therapy may be considered only when combined with OFS.

\section{OFS Combined with Tamoxifen and/or Chemotherapy} $\nabla$

An EBCTCG meta-analysis of the randomised trials published in 2005 failed to find evidence that ovarian function suppression or oophorectomy combined with chemotherapy offer any benefits, apart from in women younger than 40 , for whom it may possibly be beneficial [10].

A study of over 1500 pre-menopausal high-risk patients compared the efficacy of CAF chemotherapy alone with that of CAF + OFS (CAF-Z) and of CAF + OFS + TAM (CAF-ZT). With a median follow-up of 9.6 years, compared to CAF-Z, CAF-ZT demonstrated improved DFS but not OS. Adding OFS to CAF did not demonstrate any overall benefits. In an unplanned retrospective analysis, however, women younger than 40 undergoing OFS showed improved DFS [28].

Cuzick et al. [29] also performed a meta-analysis of individual patient data from 16 published trials in which 11906 pre-menopausal women (including 2884 with receptor-negative tumours; at study begin, receptor analysis was not a standard technique, see above) had undergone OFS. In a sub-group of 1013 women in whom TAM was compared with TAM plus OFS, no significant differences in survival rates were observed. If this sub-group is sub-divided into women younger than 40 and women older than 40 , however, a measurable, but not statistically significant benefit of the combination of OFS and TAM can be observed for the younger women. In the group of patients who had undergone chemotherapy, OFS demonstrated significant benefits for women younger than 40 regardless of adjuvant TAM therapy ( Table 3 ).

These analyses coincide with the results of the EBCTCG metaanalysis and with a Cochrane analysis [11] that show that women younger than 40 benefit from OFS combined with chemotherapy without TAM and may benefit from OFS combined with TAM without chemotherapy.

Younger women have a lower risk of permanent CIA than older women [16-18]. This may explain why women younger than 40 are observed to benefit from OFS.

Since today the standard therapy for women with receptor-positive tumours comprises TAM alone or following chemotherapy, the option of combining chemotherapy with OFS is generally not considered for pre-menopausal women. However, the question as to whether OFS in addition to TAM or in addition to TAM + chemotherapy offers significant benefits is relevant. The meta-analyses do not answer this question.

\section{OFS Combined with Tamoxifen or Als}

$\nabla$

CIA appears to be a good prognostic factor $[16,17]$. However, to date no data have been available that demonstrate the benefits of administering OFS after resumption of menstruation [11,29]. The randomized SOFT and TEXT trials studied the effect of 5-year endocrine therapy with a combination of TAM or the AI exemestane with OFS in pre-menopausal patients with receptor-positive breast cancer $[4,5]$. OFS was achieved with the GnRH agonist triptorelin or with oophorectomy or radiation therapy to the ovaries. For the TEXT trial, 2672 patients underwent OFS combined with either TAM or exemestane no later than 12 weeks post-surgery. The SOFT trial treated 3066 women. Stratification was undertaken according to whether adjuvant chemotherapy was performed. Patients were included who did not undergo chemotherapy ( $46.7 \%$ of the patients) or who had remained pre-menopausal within 8 months after completion of the chemotherapy (53.3\%). The patients were randomly allocated to 3 groups: TAM alone, OFS + TAM, or OFS + exemestane. The combined results of the 2 trials showed benefits for OFS only in patients whose risk was so high that chemotherapy was indicated. The efficacy of 
Table 4 Ovarian function suppression plus aromatase inhibitors compared to tamoxifen with ovarian function suppression in adjuvant therapy of pre-menopausal patients with hormone receptor-positive breast cancer. Results of the ABCSG-12 trial (GnRH + anastrozole/tamoxifen for 3 years) and the combined analysis of the TEXT and SOFT trials (OFS + exemestane/tamoxifen for 5 years). In the ABCSG-12 trial, 1803 patients were analysed and in the SOFT/TEXT trials, 4690 (of a total of 4717 ) patients were analysed. Half the patients in the ABCSG-12 trial also received zoledronic acid for 3 years. This group showed significantly better DFS and non-significantly better OS than the group not receiving zoledronic acid. For the TEXT and SOFT trials, the DFS was also reported dependent on the administration of chemotherapy. $42.6 \%$ of the patients did not undergo chemotherapy, while $57.4 \%$ underwent chemotherapy either after (TEXT) or before (SOFT) randomization (modified after [3-5]).

\begin{tabular}{|c|c|c|c|c|c|c|c|c|c|c|c|}
\hline \multirow{2}{*}{\multicolumn{2}{|c|}{ Median follow-up }} & \multicolumn{5}{|c|}{ TEXT/SOFT } & \multicolumn{5}{|c|}{ ABCSG-12 } \\
\hline & & \multicolumn{5}{|c|}{5.7 years } & \multicolumn{5}{|c|}{7.9 years } \\
\hline \multicolumn{2}{|l|}{ Median age } & \multicolumn{5}{|c|}{43 years } & \multicolumn{5}{|c|}{45 years } \\
\hline & & $\mathrm{n}$ & $\begin{array}{l}\text { OFS + AI } \\
(\%)\end{array}$ & $\begin{array}{l}\text { OFS }+ \\
\text { TAM (\%) }\end{array}$ & $\mathrm{RR}(\mathrm{Cl})$ & p & $\mathbf{n}$ & $\begin{array}{l}\text { OFS + Al } \\
\text { (\%) }\end{array}$ & $\begin{array}{l}\text { OFS + } \\
\text { TAM (\%) }\end{array}$ & $\mathrm{RR}(\mathrm{Cl})$ & $\mathbf{p}$ \\
\hline DFS & & 4690 & 91.1 & 87.3 & $\begin{array}{l}0.72 \\
(0.60-0.85)\end{array}$ & $<0.001$ & 1803 & 85.2 & 87.0 & $\begin{array}{l}1.13 \\
(0.88-1.45)\end{array}$ & 0.33 \\
\hline \multirow[t]{2}{*}{$\begin{array}{l}\text { DFS with- } \\
\text { out chemo }\end{array}$} & TEXT & 1053 & 96.1 & 93.0 & $\begin{array}{l}0.54 \\
(0.32-0.92)\end{array}$ & & & & & & \\
\hline & SOFT & 943 & 95.8 & 93.1 & $\begin{array}{l}0.68 \\
(0.38-1.19)\end{array}$ & & & & & & \\
\hline \multirow[t]{2}{*}{$\begin{array}{l}\text { DFS with } \\
\text { chemo }\end{array}$} & TEXT & 1607 & 89.8 & 84.6 & $\begin{array}{l}0.69 \\
(0.53-0.90)\end{array}$ & & & & & & \\
\hline & SOFT & 1087 & 84.3 & 80.6 & $\begin{array}{l}0.84 \\
(0.62-1.13)\end{array}$ & & & & & & \\
\hline OS & & 4690 & 95.9 & 96.9 & $\begin{array}{l}1.15 \\
(0.86-1.51)\end{array}$ & 0.37 & 1803 & 94.1 & 96.3 & $\begin{array}{l}1.63 \\
(1.05-2.52)\end{array}$ & 0.03 \\
\hline
\end{tabular}

RR: relative risk, Cl: 95\% confidence interval, DFS: disease-free survival, OS: overall survival, OFS: ovarian function suppression, Al: aromatase inhibitor, TAM: tamoxifen, with chemo: with chemotherapy, n: number of patients, without chemo: patients without chemotherapy, with chemo: patients with chemotherapy

the AI exemestane combined with OFS was superior to that of TAM combined with OFS. The 5-year overall survival rate in the 2 trials was over $95 \%$ in all groups. The observation period is still too short to make a statistically valid statement about potential differences in OS.

In a joint analysis of the TEXT and SOFT trials with 4690 patients [4] who underwent OFS, after a median observation period of 68 months, the 5-year disease-free survival rate (DFS: no recurrence and no invasive secondary cancer of the breast or other organs) and the breast cancer-free survival rate (BFS: no incidents of breast cancer) in the group treated with exemestane were significantly better than in the group treated with tamoxifen (DFS 91.1 vs. $87.3 \%$; hazard ratio (HR) 0.72 ; $95 \%$ confidence interval $(\mathrm{CI})$ $0.60-0.85$; $\mathrm{p}<0.001$; BFS 92.8 vs. $88.8 \%$; HR 0.66; CI 0.55-0.80; $\mathrm{p}<0.001)($ Tables 4 and 5$)$.

In the SOFT trial [5] no significant benefit of OFS in addition to TAM for 5-year DFS was observed after 67 months median observation in patients both with and without chemotherapy. (overall group: TAM monotherapy $84.7 \%$; TAM plus OFS $86.6 \%$; HR 0.83 , CI $0.66-1.04 ; \mathrm{p}=0.10$; patients with chemotherapy: TAM monotherapy $78.0 \%$, TAM + OFS 82.5\%; HR 0.78; CI 0.60-1.02). A significant difference was observed between TAM monotherapy and exemestane plus OFS in the group of patients who had undergone chemotherapy due to increased risk. The 5-year breast cancer survival rate was $85.7 \%$ for OFS plus exemestane and $78.0 \%$ for TAM monotherapy (HR 0.65; CI 0.49-0.87). The most obvious benefit obtained from OFS was observed in the group of women younger than $35,94 \%$ of whom had undergone chemotherapy. BFS after 5 years was $67.7 \%$ for TAM monotherapy, $78.9 \%$ for TAM plus OFS, and $83.4 \%$ for exemestane plus OFS. However, the number of cases included in the analysis, at 233, was too low for a valid statistical statement to be made ( 0 Tables 4 and 5 ).
The ABCSG-12 trial treated 1803 pre-menopausal patients with hormone receptor-positive breast cancer and fewer than 10 affected lymph nodes for 3 years with a combination of GnRH analogues and the AI anastrozole or TAM. Most of the patients did not undergo chemotherapy. After a median 94.4-month observation period, no benefits of anastrozole for DFS were observed compared to TAM. In fact, the mortality rate for the group treated with anastrozole was significantly higher $(\mathrm{HR}=1.63$; CI $1.05-$ 1.45; $\mathrm{p}=0.030$ ) [3] ( $\bigcirc$ Tables 4 and 5).

The reason for the discrepancy between the results of ABCSG-12 and TEXT/SOFT is unclear. In the ABCSG-12 trial, the endocrine therapy was carried out for 3 years as compared to 5 years for the SOFT and TEXT trials. However, despite the shorter treatment period and the relatively high risk - around one third of the patients were node-positive with up to 9 lymph nodes affected and only $5.8 \%$ had undergone chemotherapy - DFS after 5 years in this trial, at $94 \%$, was also very high [3]. The different results cannot be explained by differences in the efficacy of the AIs used [26, 27].

\section{Absolute and Relative Benefits of Adjuvant Therapies \\ $\nabla$}

The therapeutic effects mentioned so far entail relative improvements valid for a group of patients. For individual patients, only the absolute benefit is relevant. The absolute benefit is derived from the mortality risk and the relative benefit. The lower a tumour's risk of recurrence and mortality, the lower the individual benefit of a therapy [6]. 
Table 5 Survival rates after tamoxifen monotherapy compared to tamoxifen or exemestane combined with ovarian function suppression and dependent on administration of chemotherapy. Results of the SOFT trial. 3066 patients were randomly allocated to 3 groups that received either tamoxifen monotherapy, tamoxifen plus ovarian function suppression, or exemestane plus ovarian function suppression for 5 years. $46.7 \%$ of the patients did not undergo chemotherapy and $53.3 \%$ underwent chemotherapy and remained pre-menopausal (modified after [5]).

\begin{tabular}{|c|c|c|c|c|c|c|}
\hline & & \multicolumn{5}{|l|}{ SOFT } \\
\hline \multicolumn{2}{|l|}{ Median follow-up } & \multicolumn{5}{|c|}{5.7 years } \\
\hline \multirow[t]{2}{*}{ Median age } & & \multicolumn{5}{|c|}{ Total: 43 years; without chemo: 46 years; with chemo: 40 years } \\
\hline & & $\mathbf{n}$ & 5-year \% & HR & $\mathrm{Cl}$ & Significance \\
\hline \multirow[t]{3}{*}{ DFS } & TAM & 1018 & 84.7 & 1 & & \\
\hline & $\mathrm{TAM}+\mathrm{OFS}$ & 1015 & 86.6 & 0.83 & $0.66-1.04$ & ns \\
\hline & $\mathrm{Al}+\mathrm{OFS}$ & 1014 & 89.0 & 0.68 & $0.53-0.86$ & s \\
\hline \multirow[t]{3}{*}{ DFS without chemo } & TAM & 476 & 93.3 & & & \\
\hline & TAM + OFS & 473 & 93.4 & 0.83 & $0.52-1.34$ & ns \\
\hline & $\mathrm{Al}+\mathrm{OFS}$ & 470 & 95.2 & 0.61 & $0.36-1.03$ & ns \\
\hline \multirow[t]{3}{*}{ DFS with chemo } & TAM & 542 & 77.1 & & & \\
\hline & $\mathrm{TAM}+\mathrm{OFS}$ & 542 & 80.7 & 0.82 & $0.64-1.07$ & ns \\
\hline & $\mathrm{Al}+\mathrm{OFS}$ & 544 & 83.8 & 0.70 & $0.53-0.92$ & S \\
\hline \multirow[t]{3}{*}{ OS } & TAM & 1018 & 95.1 & & & \\
\hline & $\mathrm{TAM}+\mathrm{OFS}$ & 1015 & 96.7 & 0.74 & $0.51-1.09$ & ns \\
\hline & $\mathrm{Al}+\mathrm{OFS}$ & 1014 & 95.3 & 0.97 & $0.68-1.40$ & ns \\
\hline \multirow[t]{3}{*}{ OS without chemo } & TAM & 476 & 99.8 & & & \\
\hline & TAM + OFS & 473 & 99.2 & 3.84 & $0.81-18.08$ & ns \\
\hline & $\mathrm{Al}+\mathrm{OFS}$ & 470 & 98.8 & 4.03 & 0.86-18.99 & ns \\
\hline \multirow[t]{3}{*}{ OS with chemo } & TAM & 542 & 90.9 & & & \\
\hline & $\mathrm{TAM}+\mathrm{OFS}$ & 542 & 94.5 & 0.64 & $0.4-0.96$ & s \\
\hline & $\mathrm{Al}+\mathrm{OFS}$ & 544 & 92.3 & 0.87 & $0.59-1.27$ & ns \\
\hline
\end{tabular}

HR: hazard ratio, Cl: 95\% confidence interval, DFS: disease-free survival, OS: overall survival, OFS: ovarian function suppression, Al: aromatase inhibitor, TAM: tamoxifen, with chemo: with chemotherapy, n: number of patients, ns: not significant, s: significant, without chemo: patients without chemotherapy, with chemo: patients with chemotherapy

\section{Side Effects and Compliance \\ $\nabla$}

Side effects, most often in the form of menopausal symptoms are common during endocrine therapy. The severity of the side effects varies widely from patient to patient, independent of the oncological treatment benefit.

The oncological benefits of endocrine therapy are achieved only if compliance is high, meaning that the patient must take the recommended dose regularly over the planned period. The more the therapy period or the dose density deviate from the recommendations, the lower the therapeutic effect will be. In patients whose compliance was less than $60 \%$, mortality increases by a factor of up to 3.6 compared to patients with full compliance [30]. The long duration of endocrine therapy, comprising 5 to 10 years, requires a high level of motivation on the part of the patient and makes it particularly susceptible to early discontinuation. For this reason, the compliance reported in trials cannot be transferred to routine treatment. In endocrine therapy trials, a relatively high compliance level is achieved. In year 5, over two-thirds of the participants are usually still compliant. This was shown by the IBIS-II prevention trial, for example, which recruited healthy subjects in order to test whether an AI can prevent breast cancer [31]. During routine treatment, this compliance level is not reached, as numerous studies have shown. These studies report that in year 5 , only around half the patients are still undergoing the endocrine therapy [30,32]. In addition to inadequate awareness about the value of the therapy and waning motivation, side effects are often responsible for the patient discontinuing the therapy. While muscle and joint pain, as well as menopausal symptoms, are typical side effects of endocrine therapy, they are also typical symptoms of ageing. The need to explain the reason for the symptoms makes patients attribute new symptoms to the therapy, even if there is no causal relation. This is especially true if the package insert describes these symptoms as possible side effects of the therapy. A current study shows that the odds of treatment discontinuation were higher in patients who reported a greater number of symptoms (poor sleep quality, fatigue, mood swings, anxiety, difficulty concentrating) prior to treatment initiation. If 3 to 5 of these symptoms were already in place prior to treatment initiation, the likelihood of the patient discontinuing AI therapy was twice as high as for women with no more than 2 such symptoms [33].

Unfortunately, physicians apparently do not address adequately the symptoms occurring during hormonal therapy when they counsel their patients. Comparative studies show that patients experience side effects much more frequently and intensively than physicians realize [34]. If they are not addressed, they cannot be treated.

For this reason, when selecting the optimal treatment, compliance during the entire planned therapy period must be taken into consideration. No matter how effective treatment may be, if it is discontinued early by the patient due to lack of acceptance or side effects that cannot be treated properly, it will be less beneficial than a therapy that is considered to be second-best in terms of study results but is in fact accepted and carried out. It may be more worthwhile to implement a limited range of therapy modalities with optimal patient compliance than to carry out a number of interventions with only half-hearted compliance.

This aspect must be taken into account when translating the data from the TEXT and SOFT trials into clinical routine.

These trials reported significant differences in the side effect rate $[4,5]$. The side effects included typical menopausal symptoms 
Premenopausal patients - adjuvant endocrine therapy

\begin{tabular}{|c|c|c|c|}
\hline & \multicolumn{2}{|c|}{ Oxford } & \multirow[t]{2}{*}{ AGO } \\
\hline & LoE & GR & \\
\hline - Tamoxifen* $5-10$ years & $1 a$ & A & ++ \\
\hline $\begin{array}{l}\text { GnRHa alone (only if relevant } \\
\text { contraindications for TAM) }\end{array}$ & $1 a$ & B & + \\
\hline
\end{tabular}

In patients with ovarian function (within 8 months) after adjuvant chemotherapy (exploratory retrospective analysis suggests higher benefit in younger age) ${ }^{* *}$ :

\begin{tabular}{|c|c|c|c|}
\hline - OFS ${ }^{\#} 5$ years + TAM 5 years & $1 b$ & B & $+1-$ \\
\hline - OFS $^{\#} 5$ years $+\mathrm{Al} 5$ years & $1 b$ & B & $+1-$ \\
\hline
\end{tabular}

* Treat as long as tolerable and premenopausal, switch to Al optional when patient turned postmenopausal.

\# Increased side effects may impair compliance. High compliance to TAM is more effective than addition of $\mathrm{GnRH}$ or treatment with $\mathrm{GnRH}+$ Al with impaired compliance.

** Duration of treatment may be prolonged to up to 10 years using TAM.

Fig. 1 Guidelines of the AGO Breast Committee on tamoxifen and ovarian function suppression in adjuvant therapy of pre-menopausal women with hormone-sensitive breast cancer (OFS: ovarian function suppression, LoE: level of evidence, GR: grade of recommendation according to Oxford guidelines, AGO: recommendation of the AGO Breast Committee) [35].

\section{Adjuvant endocrine therapy}

\begin{tabular}{cc|c|c|c|c|c|c|c|c|} 
Oxford & AGO \\
LOE GR
\end{tabular}

Standard therapy in endocrine responsive tumors:

\begin{tabular}{|c|c|c|c|}
\hline - Endocrine therapy & 1a & A & ++ \\
\hline $\begin{array}{l}\text { Chemotherapy followed by endocrine } \\
\text { therapy (dependent on individual risk } \\
\text { and tumor biology) }\end{array}$ & $1 a$ & A & ++ \\
\hline
\end{tabular}

Fig. 2 Guidelines of the AGO Breast Committee on adjuvant endocrine therapy and chemotherapy of pre-menopausal women with hormonesensitive breast cancer (LoE: level of evidence, GR: grade of recommendation according to Oxford guidelines, AGO: recommendation of the AGO Breast Committee) [35].

such as hot flushes, sweating, loss of libido, vaginal dryness, poor sleep quality, depression, musculoskeletal pain, hypertension, impaired glucose tolerance and osteoporosis. Level 3 and 4 toxicity was reported by $23.7 \%$ of participants using tamoxifen monotherapy (SOFT trial), while in the groups with OFS (SOFT and TEXT trials) and exemestane, it was reported by $30.5 \%$ of the participants and for the groups with OFS and TAM, by $29.4 \%$ of participants. Osteoporosis (T-score $<-2.5$ ) was diagnosed in $3.5 \%$ of patients undergoing tamoxifen monotherapy, in $6.4 \%$ of patients undergoing OFS plus TAM, and in $13.2 \%$ using OFS plus exemestane, respectively.

The higher side effect rate associated with OFS may be accompanied by the risk of reduced compliance. While with the combination of OFS and TAM, treatment is still effective if one of the treatment components is discontinued, in the combination of OFS and exemestane, discontinuing OFS stops the oncological efficacy of exemestane. The activation of ovarian function stimulated by the AI could even be damaging. For this reason, the benefits of OFS, which based on current analysis are limited to DFS in women who have undergone chemotherapy, must be weighed against the higher rate of side effects and the risk of compromised compliance.

Combined therapy with OFS and TAM and especially with OFS and exemestane should therefore be initiated only if long-term high-quality care for the patient and a high level of reliability on the part of the patient are absolutely guaranteed. Otherwise, the therapy may lead to a worse prognosis rather than a better one.

\section{AGO Breast Committee Guidelines}

\section{$\nabla$}

For these reasons, the AGO Breast Committee currently recommends prudence when prescribing OFS combined with TAM or exemestane for pre-menopausal women. It does not recommend this therapy as the standard treatment but instead mentions it as a treatment option on a case-by-case basis, for example, for women younger than 35 with reliable long-term gynaecological care in whom high compliance can be anticipated and who are undergoing chemotherapy due to a high risk of recurrence and have resumed an ovarian cycle within 6 months. For pre-menopausal women, 5-year treatment with TAM is still the gold standard. Depending on the risk situation and the tumour biology, this treatment is carried out after the patient has undergone chemotherapy and/or it is extended to 10 years. If the patient becomes post-menopausal during endocrine therapy, the sequence with an AI also makes sense ( $\bullet$ Figs. 1 and 2) [35].

\section{Conflict of Interest}

$\nabla$

No conflicts of interest with respect to the content of the publication.

\section{References}

1 Scharl A, Salterberg A. Multimodale Therapie des nicht metastasierten Mammakarzinoms. Onkologe 2014; 4: 379-394

2 Love RR, Philips J. Oophorectomy for breast cancer: history revisited. J Natl Cancer Inst 2002; 94: 1433-1434

3 Gnant M, Mlineritsch B, Stoeger $H$ et al. Zoledronic acid combined with adjuvant endocrine therapy of tamoxifen versus anastrozol plus ovarian function suppression in premenopausal early breast cancer: final analysis of the Austrian Breast and Colorectal Cancer Study Group Trial 12. Ann Oncol 2015; 26: 313-320

4 Pagani O, Regan MM, Walley BA et al. Adjuvant exemestane with ovarian suppression in premenopausal breast cancer. N Engl J Med 2014; 371: 107-118

5 Francis PA, Regan MM, Fleming GF et al. Adjuvant ovarian suppression in premenopausal breast cancer. N Engl J Med 2015; 372: 436-446

6 Scharl A, Kühn T, Papathemelis T et al. The right treatment for the right patient - personalised treatment of breast cancer. Geburtsh Frauenheilk 2015; 75: 683-691

7 Jordan VC. Tamoxifen (ICI46,474) as a targeted therapy to treat and prevent breast cancer. Br J Pharmacol 2006; 147 (Suppl. 1): S269-S276

8 Scharl A, Vierbuchen M, Würz H. Immunhistochemischer Nachweis von Östrogen- und Progesteronrezeptoren beim Mammakarzinom mit Hilfe monoklonaler Antikörper: Vergleich mit der biochemischen Rezeptoranalyse. Pathologe 1989; 10: 31-38

9 Early Breast Cancer Trialists' Collaborative Group. Systemic treatment of early breast cancer by hormonal, cytotoxic, or immune therapy. 133 randomised trials involving 31,000 recurrences and 24,000 deaths among 75,000 women. Lancet 1992; 339: 1-15, 71-85 
10 Early Breast Cancer Trialists' Collaborative Group. Effects of chemotherapy and hormonal therapy for early breast cancer on recurrence and 15-year survival: an overview of the randomised trials. Lancet 2005; 365: 1687-1717

11 Goel S, Sharma R, Hamilton A et al. LHRH agonists for adjuvant therapy of early breast cancer in premenopausal women. Cochrane Database Syst Rev 2009; 4: CD004562

12 Pritchard K. Endocrinology and hormone therapy in breast cancer: Endocrine therapy in premenopausal women. Breast Cancer Res 2005; 7: 70-76

13 Jakesz R, Hausmaninger H, Kubista E et al.; Austrian Breast and Colorectal Cancer Study Group Trial 5. Randomized adjuvant trial of tamoxifen and goserelin versus cyclophosphamide, methotrexate, and fluorouracil: evidence for the superiority of treatment with endocrine blockade in premenopausal patients with hormone-responsive breast cancerAustrian Breast and Colorectal Cancer Study Group Trial 5. J Clin Oncol 2002; 20: 4621-4627

14 Kaufmann M, Jonat W, Blamey R et al.; Zoladex Early Breast Cancer Research Association (ZEBRA) Trialists' Group. Survival analyses from the ZEBRA study. goserelin (Zoladex) versus CMF in premenopausal women with node-positive breast cancer. Eur J Cancer 2003; 39: 1711-1717

15 Ejlertsen B, Mouridsen HT, Jensen MB et al. Similar efficacy for ovarian ablation compared with cyclophosphamide, methotrexate, and fluorouracil: from a randomized comparison of premenopausal patients with node-positive, hormone receptor-positive breast cancer. J Clin Oncol 2006; 24: 4956-4962

16 Walshe JM, Denduluri N, Swain SM. Amenorrhea in premenopausal women after adjuvant chemotherapy for breast cancer. J Clin Oncol 2006; 24: 5769-5779

17 Swain SM, Jeong JH, Geyer CE jr. et al. Longer therapy, iatrogenic amenorrhea, and survival in early breast cancer. N Engl J Med 2010; 362: 2053-2065

18 International Breast Cancer Study Group; Colleoni M, Gelber S, Goldhirsch A et al. Tamoxifen after adjuvant chemotherapy for premenopausal women with lymph node-positive breast cancer: International Breast Cancer Study Group Trial 13-93. J Clin Oncol 2006; 24: 13321341

19 Early Breast Cancer Trialists' Collaborative Group (EBCTCG); Davies C, Godwin J, Gray R et al. Relevance of breast cancer hormone receptors and other factors to the efficacy of adjuvant tamoxifen: patient-level meta-analysis of randomised trials. Lancet 2011; 378: 771-784

20 Davies C, Pan H, Godwin J et al.; Adjuvant Tamoxifen: Longer Against Shorter (ATLAS) Collaborative Group. Long-term effects of continuing adjuvant tamoxifen to 10 years versus stopping at 5 years after diagnosis of oestrogen receptor-positive breast cancer: ATLAS, a randomised trial. Lancet 2013; 381: 805-816

21 Gray RG, Rea D, Handley Ket al. aTTom: Long-term effects of continuing adjuvant tamoxifen to 10 years versus stopping at 5 years in 6,953 women with early breast cancer. J Clin Oncol 2013; 31 (Suppl.): Abstr. 5

22 Delozier T, Switsers O, Genot JY et al. Delayed adjuvant tamoxifen: tenyear results of a collaborative randomized controlled trial in early breast cancer (tam-02 trial). Ann Oncol 2000; 11: 515-519
23 Söreide JA, Varhaug JE, Fjösne HE et al. Adjuvant endocrine treatment (goserelin vs. tamoxifen) in pre-menopausal patients with operable node positive stage II breast cancer. A prospective randomized national multicenter study. Eur J Surg Oncol 2002; 28: 505-510

24 Diamond MP, Legro RS, Coutifaris C et al.; NICHD Reproductive Medicine Network. Letrozole, gonadotropin, or clomiphene for unexplained infertility. N Engl J Med 2015; 373: 1230-1240

25 Dowsett M, Forbes JF, Bradley R et al.; Early Breast Cancer Trialists' Collaborative Group (EBCTCG). Aromatase inhibitors versus tamoxifen in early breast cancer: patient-level meta-analysis of the randomised trials. Lancet 2015; 386: 1341-1352

26 Goss PE, Ingle JN, Pritchard KI et al. Exemestane versus anastrozole in postmenopausal women with early breast cancer: NCIC CTG MA.27-a randomized controlled phase III trial. J Clin Oncol 2013; 31: 13981404

27 O'Shaughnessy J, Yardley DA, Burris HA et al. Randomized phase 3 trial of adjuvant letrozole versus anastrozole in postmenopausal patients with hormone receptor positive, node positive early breast cancer: Final efficacy and safety results of the femara versus anastrozole clinical evaluation (Face) trial. San Antonio Breast Cancer Symposium 2015; Abstr. PD2-01

28 Davidson NE, O'Neill AM, Vukov AM et al. Chemoendocrine therapy for premenopausal women with axillary lymph node-positive, steroid hormone receptor-positive breast cancer: results from INT 0101 (E5188). J Clin Oncol 2005; 23: 5973-5982

29 Cuzick J, Ambroisine L, Davidson N et al.; LHRH-agonists in Early Breast Cancer Overview group. Use of luteinising-hormone-releasing hormone agonists as adjuvant treatment in premenopausal patients with hormone-receptor-positive breast cancer: a meta-analysis of individual patient data from randomised adjuvant trials. Lancet 2007; 369: 1711-1723

30 Hershman DL, Shao T, Kushi LH et al. Early discontinuation and non-adherence to adjuvant hormonal therapy are associated with increased mortality in women with breast cancer. Breast Cancer Res Treat 2011; 126: 529-537

31 Cuzick J, Sestak I, Forbes JF et al. Anastrozole for prevention of breast cancer in high-risk postmenopausal women (IBIS-II): an international, double-blind, randomised placebo-controlled trial. Lancet 2014; 383: 1041-1048

32 Hadji P, Ziller V, Kyvernitakis J et al. Persistence in patients with breast cancer treated with tamoxifen or aromatase inhibitors: a retrospective database analysis. Breast Cancer Res Treat 2013; 138: 185-191

33 Kidwell KM, Harte SE, Hayes DF et al. Patient-reported symptoms and discontinuation of adjuvant aromatase inhibitor therapy. Cancer 2014; 120: 2403-2411

34 Fellowes D, Fallowfield LJ, Saunders CM et al. Tolerability of hormone therapies for breast cancer: how informative are documented symptom profiles in medical notes for 'well-tolerated' treatments? Breast Cancer Res Treat 2001; 66: 73-81

35 Kommission Mamma der AGO. Adjuvant endocrine therapy in pre- and postmenopausal patients. Online: http://www.ago-online.de/ fileadmin/downloads/leitlinien/mamma/Maerz2016/en/2016E\% 2010_Adjuvant\%20Endocrine\%20Therapy\%20in\%20Pre-\%20and\% 20ostmenopausal\%20\%20Patients.pdf; last access: 04.04 .2016 